"This is an Author's Accepted Manuscript of an article published in [include the complete citation information for the final version of the article as published in the International Journal of Medical Science, 2018. The final publication is available at https://doi.org/10.1007/ s11845-018-1806-1". 


\section{A Profile of Physiotherapy Supply in Ireland}

James Eighan ${ }^{1}$, Brendan Walsh ${ }^{1}$, Samantha Smith $^{1}$, Maev-Ann Wren $^{1}$, Steve Barron ${ }^{2}$, Edgar Morgenroth ${ }^{1,3}$

${ }^{1}$ Economic and Social Research Institute, Whittaker Square, Sir John Rogerson's Quay, Dublin 2, Dublin

${ }^{2}$ University College, Dublin, Ireland, formerly ESRI (until December 2015)

${ }^{3}$ Dublin City University Business School

Corresponding Author

James Eighan

Email: james.eighan@esri.ie

Tel.: +353 (0)1 8632056

Acknowledgements

The authors thank Des Williams (Health Service Executive), and the Irish Society of Chartered Physiotherapists for provision, support, and advice in using the data. This work was supported by the Health Research Board (Grant No. 4644727). The views expressed are those of the authors and not necessarily of the Health Research Board. 


\section{Introduction}

It is essential for policymakers to have information on the numbers and geographic distribution of the health workforce when planning current and future resource allocation requirements. However, within mixed public/private healthcare systems, such as the Irish system, the lack of information on private healthcare workers makes resource allocation decisions more difficult. This is especially the case for physiotherapy where private care plays an important role in the provision of services. While the overall supply of physiotherapy is available for many countries, such as the UK $(51,662$ community-based physiotherapists; 8 per 10,000 people [1]), no recent all-encompassing figures have been available for Ireland.

One reason for this may be that the registration of physiotherapists has only recently become mandatory.

There were an estimated 1,300 and 1,700 physiotherapists practising in Ireland in 2001 and 2004 respectively [2,3]. However, as these figures were not disaggregated by public/private sector and acute/non-acute work setting, they fail to capture how physiotherapy services are provided. Some recent studies have examined physiotherapy in Ireland with respect to musculoskeletal [4] and physical activity pathways [5] respectively. However, such studies are difficult to contextualise due to the lack of an estimate of total community physiotherapy supply.

The main aims of this analysis are to quantify the total supply of physiotherapists working in Ireland; to profile the geographic distribution of publicly- and privately-practising physiotherapists who work in a non-acute setting; to identify if there are geographical inequalities in this geographic distribution; and to ascertain if private physiotherapy supply may substitute for public care in some areas. 


\section{Data}

This paper uses a number of different datasets. First, data on all physiotherapists employed in December 2014 by the Health Service Executive (HSE), were obtained from the Health Service Personnel Census (HSPC). The HSPC records numbers and whole-time equivalent (WTE), by gender, at the end of each month of all staff directly employed by the HSE. ${ }^{1}$ Staff numbers are disaggregated by grade, functional area, acute and non-acute categories and Local Health Office (LHO).

Second, data on private and state-subsidised voluntary physiotherapists that were not captured in the HSPC were obtained from the register of members of the Irish Society of Chartered Physiotherapists (ISCP). The ISCP is the representative body for chartered physiotherapists and the Irish representative of the World Confederation for Physical Therapy. Recognition of qualifications by, and membership of, the ISCP are required for private and public practitioners to use the title 'Chartered Physiotherapist'. While registration was not mandatory at the time of the research, the ISCP was the only authority that had approval from the Minister for Health to recognise Irish physiotherapy qualifications until September 2016, and therefore its register is expected to include virtually all practising voluntary and private physiotherapists in Ireland. ${ }^{2}$ This includes personnel employed in state-subsidised voluntary organisations, who are not recorded in the HSPC. ${ }^{3}$ The ISCP register includes data on physiotherapist practice location, job title, employment sector (public, private, private and voluntary, education or other) and gender.

Third, ISCP members were surveyed in 2015 to obtain data on work patterns and practices which are not captured in the ISCP register. To maximise the response rate, the

\footnotetext{
1 Includes those employed in organisations where the HSE pays staff salaries under Section 38 of the Health Act 2005.

${ }^{2}$ Since 30 September 2016 all physiotherapists have been obliged to register by 30/09/2018 with the new professional regulator, the Health and Social Care Professionals Council (CORU): http://www.coru.ie/en/about_us/what_is_coru [last accessed 12/03/2018].

${ }^{3}$ The HSE provides these organisations with block grant funding under Section 39 of the Health Act 2005.
} 
survey was administered directly by the ISCP to all members (public and private) on its register. Responses were received from 576 members out of 2,607 giving a response rate of $22 \%$. The survey asked a number of questions regarding public and private practice work activity including weekly working hours, and number of weeks worked annually (to allow for calculation of WTEs) and questions on demographics of respondents (e.g. age, sex, region of work).

Population estimates in 2014 from the ESRI were used to provide the populations for each county and LHO. To account for the fact that the boundaries of some counties and LHOs are not the same, the population of each LHO broken down by its constituent counties was provided by the Health Intelligence Unit of the HSE. The LHO to county proportions calculated from these data were used to assign physiotherapy supply in the HSPC to counties. In order to adjust county populations for need and eligibility, data from the Central Statistics Office (CSO) were used to estimate mortality rates and the number of people with a disability by county. Data from the Primary Care Reimbursement Service (PCRS) on the number of individuals with medical cards by LHO were assigned to counties using the proportions calculated from the Health Intelligence Unit data.

\section{Methods}

This study estimated both the headcount number and WTE number of practising physiotherapists who work in acute and non-acute settings in Ireland, the geographic profile of WTE physiotherapists across counties and the sensitivity of this geographic profile to population needs-adjustment.

Physiotherapy headcount 
The headcount of physiotherapists was estimated using data from the HSPC and the ISCP register. Those categorised as publicly-practising in the ISCP register were excluded from this headcount as they were already counted in the HSPC. Those in the databases who were assumed not to be practising (e.g. in "corporate and health business services" and "industry" $(n<10))$ and those in "education" $(n=47)$ without a practice address, were excluded. Physiotherapist numbers were disaggregated by setting of work (acute, non-acute or both) ${ }^{4}$ and sector of employment (public, private, or both). Physiotherapists were included as privately-practising if they worked in private organisations or in non-publicly-funded voluntary organisations. Physiotherapists were included as publicly-practising if they were employed either directly by the HSE or in a publicly-funded voluntary organisation. The former are captured in the HSPC, the latter in the ISCP register.

\section{Physiotherapy Whole Time Equivalents (WTEs)}

WTE numbers were calculated to provide a more accurate estimate of physiotherapy supply as they take into account part-time working patterns and mixed public/private practising. Whole-time equivalence (one WTE) was calculated as 1,702 hours annually (46 weeks*37 hours weekly) which is the standard number of working hours and weeks for an individual in the "physiotherapist" grade defined by the 2013 Public Service Stability Agreement (20132016), otherwise known as the Haddington Road Agreement [6].

WTE data for publicly-employed physiotherapists, inclusive of maternity leave, exclusive of career breaks or overtime, were taken directly from the HSPC. The average WTE in the HSPC amongst males was 0.97 and amongst females was 0.84 . No WTE data were available from the ISCP register for publicly-funded voluntary or private physiotherapists and

\footnotetext{
${ }^{4}$ Physiotherapists who worked in the acute setting are defined as those who worked in acute hospitals ("acute hospital services" in the HSPC; those who worked in acute private hospitals in the ISCP register), while the non-acute setting is defined as physiotherapy work that is conducted in the community (e.g. local health offices, local health centres), private practices, long-term care facilities, intermediate care facilities, hospices, children's and disabled people's services, and sports facilities. In the HSPC these were classified as working in "disabilities", "mental health", "older people", "palliative care" and "primary care".
} 
these have been estimated in the following way: first, the average WTE rates for males and females in the HSPC respectively was apportioned to the headcounts of physiotherapists in publicly-funded organisations, under the assumption that these physiotherapists follow a similar working pattern to directly employed public physiotherapists. Second, a WTE rate was estimated for private physiotherapists based on the average working hours provided in the survey of ISCP members (see Figure 4 in the Appendix) using two scenarios. In the baseline scenario, a WTE was defined as 1,702 hours annually, in line with standard public hours, with those who worked at least 1,702 hours given a WTE equal to 1, and those who worked less than 1,702 hours given a WTE equal to 0.5 (part-time). The weighted average of all physiotherapists was estimated, providing an average WTE of 0.85 for males and 0.65 for females. In the second (sensitivity) scenario, the average numbers of hours worked, which were measured in 500 hour blocks in the survey (the midpoint for each block was included for each respective block) were estimated and divided by 1,702 hours. Again, weighted average of all physiotherapists was estimated, providing an average WTE of 1.08 for males and 0.74 for females.

As many physiotherapists worked in both the public and private sectors, their estimated WTEs were split using a 0.8:0.2 public/private ratio, drawing on the data from the ISCP survey. Furthermore, the WTEs of private physiotherapists who worked in both the acute and non-acute settings were also split using a 0.8:0.2 acute/non-acute ratio. This split was chosen under the assumption that these physiotherapists provided a greater proportion of their working hours to acute private hospitals as they are likely employed by acute private hospitals based upon a fixed set of hour's contracts. ${ }^{5}$

\section{Geographic Profiling}

\footnotetext{
${ }^{5}$ A sensitivity scenario using a 50:50 ratio was also undertaken, with results consistent with those reported due to the small number of physiotherapists $(n=84)$ impacted. A small number of physiotherapists who worked in both an Irish and a foreign practice (assumed to be Northern Ireland) were allocated a WTE of 0.5, as data on cross-border working patterns were unavailable.
} 
The geographic profiling of WTE physiotherapists who work in non-acute settings used the WTE estimates derived from the methods described above. Acute supply was not geographically profiled as this would have meant identifying acute hospitals. ${ }^{6}$ Furthermore, as the catchment areas of acute hospitals cover numerous counties it is less meaningful to look at acute supply in the context of inequalities in supply between counties. Owing to the lack of information on practice location, 220 physiotherapists included in the headcount were excluded from the geographic profiling analysis. In the HSPC, county of practice was determined from the address of the institution or the LHO where the individual practiced. Where LHO and county boundaries were not identical, staff in LHOs were apportioned to counties based upon share of their population in each LHO. Per-capita physiotherapy supply for 28 counties (Tipperary and Dublin are divided into North and South) was estimated using the 2014 ESRI population estimates, which are described in detail in previous applications $[7,8]$. The supply of physiotherapist WTEs in each county was disaggregated into public and private supply.

Gini coefficients were used to measure the inequality in the distribution of per capita supply. Gini coefficients estimate the proportion of all physiotherapy supply located in each county, providing a measure of inequality of supply between 0 , perfect supply equality where all counties have an equally proportionate share, and 1, perfect supply inequality. Furthermore, Gini coefficients were also estimated after adjusting the population of each county by mortality and disability rates in line with previous work on healthcare needs adjustment [9]. The geographic distribution of public physiotherapists who work in nonacute settings only was also adjusted for the medical card holder population in each county

\footnotetext{
${ }^{6}$ Hospitals could not be identified due to confidentiality issues - in some counties there is only one acute hospital which would be identified were the acute supply to be geographically profiled.
} 
(medical card holders receive free, and often priority, access to public non-acute physiotherapy). ${ }^{7}$

Needs adjustment plots were estimated to show the position of the location quotient (a county's per-capita supply in relation to national per-capita supply) before and after adjustment. The unadjusted population is shown on the $y$-axis while the adjusted population is shown on the $x$-axis, for each county. ${ }^{8}$ If needs-adjustment does not change supply in a county relative to national supply, then the data point will lie on the diagonal 'line of no change'. Location quotients centred in the range $0.95-1.05$ are assumed to equate to the national average, while location quotients that fall outside this range (before and after eligibility/needs adjustment) are seen as significant changes in the ranking of a county after needs-adjusting.

\section{Results}

Figure 1 shows that there were an estimated 3,172 physiotherapists practising in Ireland in $2014 / 2015$ (panel a), which equates to 6.8 physiotherapists per 10,000 population. The majority of practising physiotherapists, $(n=2,278 ; 72 \%)$ were working primarily in the nonacute setting (4.9 per 10,000). The remaining 894 (28\%) physiotherapists were working exclusively in acute hospital care (1.9 per 10,000). Further disaggregation by public/private sector highlights a clear public/private divergence across the acute and non-acute settings. While 87 per cent of acute hospital physiotherapists worked in the public sector, only 40 per

\footnotetext{
${ }^{7}$ For example access to physiotherapy in a primary care team in Dublin South is prioritised for Medical Card holders and for clients living in the catchment area of the health centre:

http://www.hse.ie/eng/services/list/2/PrimaryCare/pcteams/dublinsouthpcts/blackrockpct/physio.html [Last accessed 02/08/2017].

While access to publicly-employed or financed physiotherapy services professionals is free at the point of use for medical card holders, this often depends upon availability in local areas [10].

${ }^{8}$ E.g. a data point in the upper left quadrant indicates a county where per capita supply is higher than the national value based on the unadjusted population (e.g., location quotient 1.5), and lower than the national value based on a needsadjusted population (e.g., location quotient 0.85 ).
} 
cent of physiotherapists who worked in a non-acute setting worked exclusively in the public sector. This reflects the fact that most acute hospitals in Ireland are public. Contrastingly, 55 per cent of those who worked in a non-acute setting $(n=1,265)$ practiced exclusively in the private sector, with a further 5 per cent $(n=107)$ practising in both the public and private sectors.

Panel $b$ of Figure 1 displays physiotherapist WTE numbers by sector after apportioning workload across acute and non-acute settings, and public and private practice, according to the baseline scenario (a similar pattern is seen under the sensitivity scenario, see Figure 5 in the Appendix). There were an estimated 2,617.1 WTE physiotherapists in Ireland in $2014 / 2015$ which equates to 5.7 WTEs per 10,000 population. There were 846.1 WTE physiotherapists (1.8 per 10,000) and 1,773.5 WTE physiotherapists $(3.8$ per 10,000$)$ working in the acute and non-acute settings respectively. This highlights that part-time physiotherapists are more prevalent in the non-acute setting. The majority of acute physiotherapy activity occurred in the public sector (755.2 WTEs vs. 90.8 in private sector). However, physiotherapists working in the non-acute setting were distributed almost evenly between the public (871.7 WTE) and private (899.4 WTE) sectors.

[Figure 1 Here]

Table 1 provides the breakdown of WTE physiotherapists working in the acute and non-acute settings by public/private split for males and females in $2014 / 2015$, under the baseline scenario. The majority $(74 \% ; n=1,940.1)$ of physiotherapy supply in Ireland is provided by females, with female physiotherapy supply accounting for 84 per cent $(n=707.3)$ of physiotherapy in the acute setting. In general, male physiotherapists were much more likely to work in the private sector (58\%) as compared to females (31\%).

Comparing the distribution of males and females across acute/non-acute settings, and public/private practice, a higher proportion of males (17\%) practiced in private hospitals 
than their female counterparts (10\%). A higher proportion of females worked in public ( $57 \%$ vs $31 \%$ for males) as opposed to private ( $43 \%$ vs $69 \%$ for males) non-acute settings.

[Table 1 Here]

Figure 2 maps the geographic distribution of non-acute setting WTE physiotherapy (both public and private) supply per 10,000 in 2014/2015 using the baseline scenario.

[Figure 2 Here]

Figure 3 provides the geographic distribution of non-acute setting WTE physiotherapy supply per 10,000 in $2014 / 2015$, disaggregated for public and private practice and for both the baseline and sensitivity scenarios. Results are similar across both scenarios, though WTE numbers are higher under the sensitivity scenario. Gini coefficients demonstrate that a statistically significant inequality in the distribution of physiotherapists exists in Ireland, with a Gini coefficient equal to $0.12(95 \% \mathrm{Cls}$ : $0.08-0.15)$ estimated. There is a large skew in supply as a consequence of large WTE figures in Dublin South in particular. ${ }^{9}$ In parts of the Greater Dublin Area, specifically Meath and Wicklow, the supply of physiotherapists was very low relative to the national value. Many counties that neighbour one another, such as Wexford and Waterford, and Carlow and Kilkenny, have very low supplies relative to the national value.

The ratio of public to private provision differs considerably across areas. While this study did not explicitly measure the public/private substitution effect, some areas with a large per-capita private supply have a correspondingly low provision of public supply. While

\footnotetext{
${ }^{9}$ The number for Dublin South includes 32.5 WTEs employed in a facility which also covers individuals from outside Dublin South. If these are excluded from the geographic analysis Dublin South has a total WTE of 4.77 per 10,000 population (second behind Leitrim) under the baseline scenario and 5.21 per 10,000 people (first in the ranking) in the sensitivity scenario.
} 
Kildare had the lowest per-capita supply of public provision, it had a relatively large percapita private supply, with over two thirds of total per-capita non-acute physiotherapy supply being private. In contrast, per-capita private supply in Monaghan was very low. Dublin South and Kerry had large per-capita supplies of both private and public physiotherapists.

[Figure 3 Here] 
Changes in a county's location quotient after needs-adjusting for mortality, disability, and Medical Card eligibility are presented in Figure 3. Few counties saw a change in their ranking after needs-adjustment, relative to the national value. All but one county, (Kildare) that had a low level of WTE supply relative to the national value pre-adjustment, had a higher level of supply relative to the national value post-adjustment for mortality. However, three counties (Mayo, Roscommon and Kerry) that had a higher level of supply relative to the national value pre-adjustment, had lower levels of relative supply post-adjustment for mortality. Little change is seen after adjusting for disability. However, some changes are observed for public supply after needs-adjusting for medical card numbers, with three areas (Mayo, Louth and Donegal) having a higher supply relative to the national value preadjustment, and a lower relative supply post-adjustment. Overall, the inequality in distribution prior to needs adjustment persists after needs adjustment.

[Figure 4 Here]

\section{Discussion}

Using a number of different data sources and methods this analysis provides the first comprehensive overview of both public and private physiotherapy supply in Ireland. These findings have important implications for resource allocation decisions in Ireland, and should facilitate more accurate comparisons of physiotherapy supply with other countries. The estimated 3,172 practising physiotherapists Ireland in $2014 / 2015$ is larger than the number reported by the OECD and Eurostat for Ireland in 2015 (which only included those in the ISCP register [11]). However, including these more comprehensive estimates into the OECD analysis, per capita physiotherapy supply in Ireland remains 30 per cent lower than the EU28 average, and much lower than countries such as Finland and Germany [12]. 
The results show that the majority (72\%) of physiotherapy supply in Ireland is provided in a non-acute setting. This is an important finding in the context of the increasing emphasis placed on providing care in the community [13-16]. Furthermore, unlike previous analysis of physiotherapy in Ireland which provided total aggregate supply [2,3], this analysis disaggregates supply into acute/non-acute settings and public/private categories. This is important information in public/private healthcare systems such as Ireland's in order to inform resource allocation decisions [17]. A majority of physiotherapists who worked in a non-acute setting worked either exclusively or partially in private practice. Contrastingly, half of non-acute physiotherapy supply is in private practice. This has important implications for how individuals engage with physiotherapists, and what role the state has in provision of public physiotherapy services. An accurate assessment of the role played by private physiotherapy in Ireland would be important, for instance, to estimate the potential cost to the Exchequer of implementing recent proposals from the all-party Oireachtas Committee on the Future of Healthcare for the introduction of universal primary care [13], with free or reduced cost access to community therapy. In addition, recent estimates from the HSE show that approximately 20 per cent of referrals to public physiotherapists are not seen within 12 weeks in primary care [18]. However, whether private supply acts as a substitute when waiting lists are long is not understood, especially for individuals who may be less able to afford private care. Previous evidence has shown that uptake of physiotherapist services is much higher among medical card holders, with user fees deterring those who must pay [19].

It is noteworthy that more physiotherapists that work in an acute setting work fulltime than those who work in a non-acute setting, which suggests that the decision to locate in the non-acute setting may also be a result of preferring greater work flexibility. These results also show that physiotherapy in Ireland is dominated by females, who are 2.9 times more numerous than male physiotherapists. Working patterns also differ for males and females considerably between the acute and non-acute, and public/private splits, with males 
working more hours than females. Similar results have been found in an Australian study, where 93 per cent of female physiotherapists worked part time in contrast to 7 per cent of male physiotherapists [20]. ${ }^{10}$

These results highlight that there is an unequal supply of non-acute physiotherapy in Ireland geographically, even after needs adjusting for mortality, disability and medical card holders (in the case of public supply). Some counties in particular have very low percapita supplies of non-acute physiotherapists, with 13 counties having fewer than three physiotherapists per 10,000, which would place these counties amongst the lowest in the EU-28 [12]. Individuals from some counties may utilise care in neighbouring counties, particularly if the supply in the neighbouring county is relatively larger, and no attempt has been made to account for this in this paper. However, many of the areas with low per-capita supply (e.g. Wexford and Waterford) also neighbour one another, which means that in some counties physiotherapy supply is not being substituted by supply in a neighbouring county. The counties which comprise the Greater Dublin Area have relatively low supplies of physiotherapists and this is in the context of increasing internal migration to this area. Results from both New Zealand and Canada (the provinces of Saskatchewan and Ontario), highlight that physiotherapy supply is also unevenly distributed in other countries [21-23]. This paper's results highlight that if the aim of treating more conditions in the community is to be realised, the inequalities in supply of primary care services, such as those for physiotherapists found in this paper, need to be rectified.

There are a number of limitations in this paper. No information on private-practising physiotherapy WTEs was available in the register. Therefore, a survey to examine working hours and patterns was carried out, with a response rate of $22 \%$. While studies have shown that physiotherapists are becoming more specialised [4], this analysis was unable to examine

\footnotetext{
${ }^{10}$ In this Australian study part-time was defined as working less than 30 hours per-week [20].
} 
specialisation, and whether geographic inequalities in specialised physiotherapy services exist. Similarly, grading levels of physiotherapists were not examined in this analysis. Some private physiotherapists may not be registered with the ISCP register, though there are incentives for physiotherapists (e.g. title recognition) to register with the ISCP.

In conclusion, this paper provides the first all-encompassing estimates of the supply of all physiotherapists in Ireland, and that significant geographic inequalities in supply exist.

\section{Compliance with ethical standards}

Funding: The work was supported by the Health Research Board grant for project number HRA-2014-HSR-659. The views expressed are those of the authors and not necessarily of the HRB.

Conflict of interest: The authors declare that they have no conflict of interest.

Ethical approval: This article does not contain any studies with human participants. 


\section{References}

1. Health and Care Professions Council (2016) Health and Care Professions Council Register Statistics: Historic. http://www.hpc-uk.org/aboutregistration/theregister/oldstats/. Accessed 17 July 2017

2. Bacon P (2001) Current and future supply and demand conditions in the labour market for certain professional therapists. Department of Health and Children, Dublin

3. Wren M-A, Tussing AD (2006) How Ireland cares: The case for health care reform. Dublin: New Island

4. French HP, Galvin R (2016) Musculoskeletal services in primary care in the Republic of Ireland: an insight into the perspective of physiotherapists. Physiotherapy. doi:10.1016/j.physio.2016.05.007

5. Barrett EM, Hussey J, Darker CD (2017) Feasibility of a physical activity pathway for Irish primary care physiotherapy services. Physiotherapy 103 (1):106-112. doi:10.1016/j.physio.2016.02.001

6. HSE (2013) Public Service Sustainability Agreement (2013 - 2016) - Haddington Road Agreement (May 2013). Health Service Executive, Dublin

7. Morgenroth E (2008) The Impact of Demographic Change on Demand for and Delivery of Health Services in Ireland 2006-2021. Report 2: Demographic Projections for the period until 2021.

https://www.esri.ie/pubs/BKMNEXT166.pdf.

8. Morgenroth E (2014) Projected Population Change and Housing Demand: A County Level Analysis. ESRI Research Note. Economic and Social Research Institute, Dublin

9. Hann M, Gravelle $H$ (2004) The maldistribution of general practitioners in England and Wales:

1974-2003. The British Journal of General Practice 54 (509):894-898

10. Citizens Information (2015) Physiotherapy services.

http://www.citizensinformation.ie/en/health/health_services/care_in_your_community/physiother apy_services.html. Accessed 4 August 2017

11. OECD (2016) OECD Health Statistics 2016: Definitions, Sources and Methods; Health Care

Resources: Physiotherapists.

12. Eurostat (2016) Healthcare personnel statistics - dentists, pharmacists and physiotherapists. http://ec.europa.eu/eurostat/statistics-explained/index.php/Healthcare_personnel_statistics__dentists,_pharmacists_and_physiotherapists\#Main_tables. Accessed 20 July 2017

13. Houses of the Oireachtas Committee on the Future of Healthcare (2017) Sláintecare Report. Houses of the Oireachtas, Dublin

14. HSE (2016) Health Service Executive National Service Plan 2016. HSE, Dublin

15. Department of the Taoiseach (2016) A Programme for a Partnership Government. Department of the Taoiseach, Dublin, Ireland

16. Daly O (2015) Primary, Community Care and Disability Services Physiotherapy Workforce and Business Review. Irish Society of Chartered Physiotherapists, Dublin

17. Brick A, Nolan A, O'Reilly J, Smith S (2010) Resource allocation, financing and sustainability in health care: Evidence for the Expert Group on Resource Allocation and Financing in the Health Sector. The Economic and Social Research Institute, Dublin, Ireland 18. HSE (2017) Primary Care Division Operational Plan. HSE, Dublin 19. McNamara A, Normand C, Whelan B (2013) Patterns and determinants of health care utilisation in Ireland. The Irish Longitudinal Study on Ageing (TILDA), Trinity College, Dublin 20. Anderson G, Ellis E, Williams V, Gates C (2005) Profile of the physiotherapy profession in New South Wales (1975-2002). Australian Journal of Physiotherapy 51 (2):109-116

21. Bath B, Gabrush J, Fritzler R, Dickson N, Bisaro D, Bryan K, Shah TI (2015) Mapping the Physiotherapy Profession in Saskatchewan: Examining Rural versus Urban Practice Patterns. Physiother Canada 67 (3):221-231. doi:10.3138/ptc.2014-53

22. Holyoke P, Verrier MC, Landry MD, Deber RB (2012) The distribution of physiotherapists in Ontario: understanding the market drivers. Physiotherapy Canada 64 (4):329-337 
23. McLean; S, Valentine; S, Shaw D (2017) Central Region's Technical Advisory Services Limited (TAS). Central TAS, Wellington

Table 1Acute and non-acute baseline scenario WTE physiotherapists (2014/2015) in Ireland by sector, practice setting, and gender

\begin{tabular}{lccc|ccc}
\hline & \multicolumn{3}{c}{ Acute Only } & \multicolumn{3}{c}{ Non-Acute } \\
\cline { 3 - 6 } Public & Female & Male & Total & Female & Male & Total \\
\cline { 2 - 6 } & 639.6 & 115.6 & 755.2 & 702.3 & 169.4 & 871.7 \\
& $(90 \%)$ & $(83 \%)$ & $(89 \%)$ & $(57 \%)$ & $(31 \%)$ & $(49 \%)$ \\
Private & 67.7 & 23.2 & 90.8 & 530.6 & 368.8 & 899.4 \\
& $(10 \%)$ & $(17 \%)$ & $(11 \%)$ & $(43 \%)$ & $(69 \%)$ & $(51 \%)$ \\
Total & $\mathbf{7 0 7 . 3}$ & $\mathbf{1 3 8 . 8}$ & $\mathbf{8 4 6 . 1}$ & $\mathbf{1 2 3 2 . 9}$ & $\mathbf{5 3 8 . 2}$ & $\mathbf{1 7 7 1 . 1}$ \\
& $\mathbf{( 1 0 0 \% )}$ & $\mathbf{( 1 0 0 \% )}$ & $\mathbf{( 1 0 0 \% )}$ & $\mathbf{( 1 0 0 \% )}$ & $\mathbf{( 1 0 0 \% )}$ & $\mathbf{( 1 0 0 \% )}$ \\
\hline
\end{tabular}


Figure 1: Headcount and WTE numbers of acute and non-acute physiotherapists in Ireland by sector $(2014 / 2015)$

a. Headcount Numbers

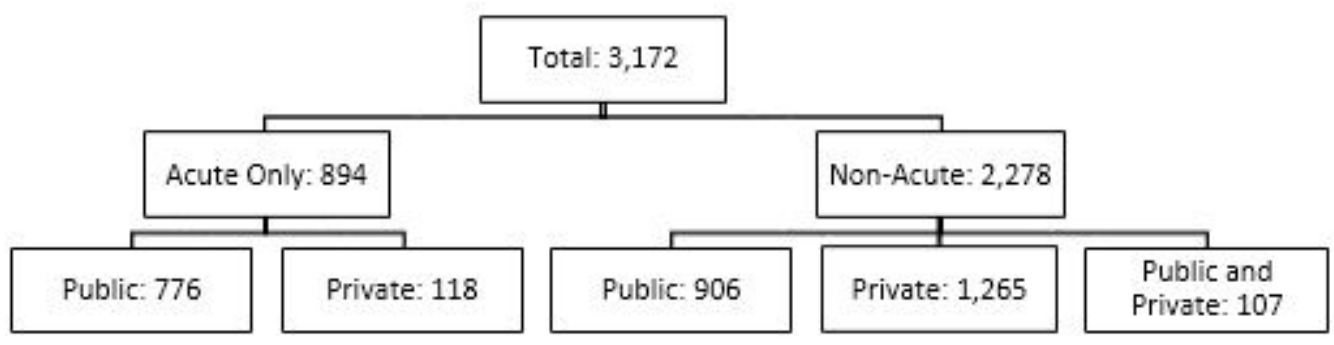

b. WTE Numbers (Baseline Scenario)

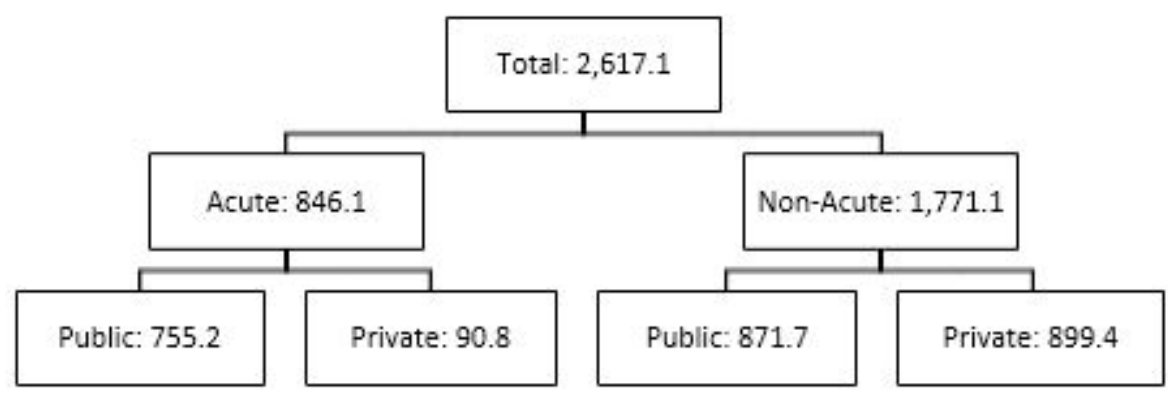

Notes: The figure for non-acute private physiotherapists includes 74 physiotherapists who also work in the public acute setting. The ESRI estimated that the Irish population was $4,633,600$ in 2014 . Therefore, the total number of physiotherapists $(3,172)$ can also be expressed as 6.8 physiotherapists per 10,000; acute physiotherapist numbers can be expressed as 1.9 per 10,000; non-acute physiotherapist numbers can be expressed as 4.9 per 10,000 . Similarly, the total number of WTE physiotherapists $(2,617.1)$ can also be expressed as 5.7 physiotherapists per 10,000 ; acute WTE physiotherapists can be expressed as 1.8 per 10,000 ; non-acute physiotherapist numbers can be expressed as 3.8 per 10,000 .

The headcount number of those categorised as working in both the public and private sectors in panel a (181) is converted to WTE using the $80: 20$ public/private split from the survey of ISCP members, described in the methods section. As this WTE is accordingly distributed between the public and private sectors, there is no "public and private" category in panel b. 
Figure 2: Geographic distribution of WTE non-acute physiotherapists per 10,000 population in Ireland $(2014 / 2015)$

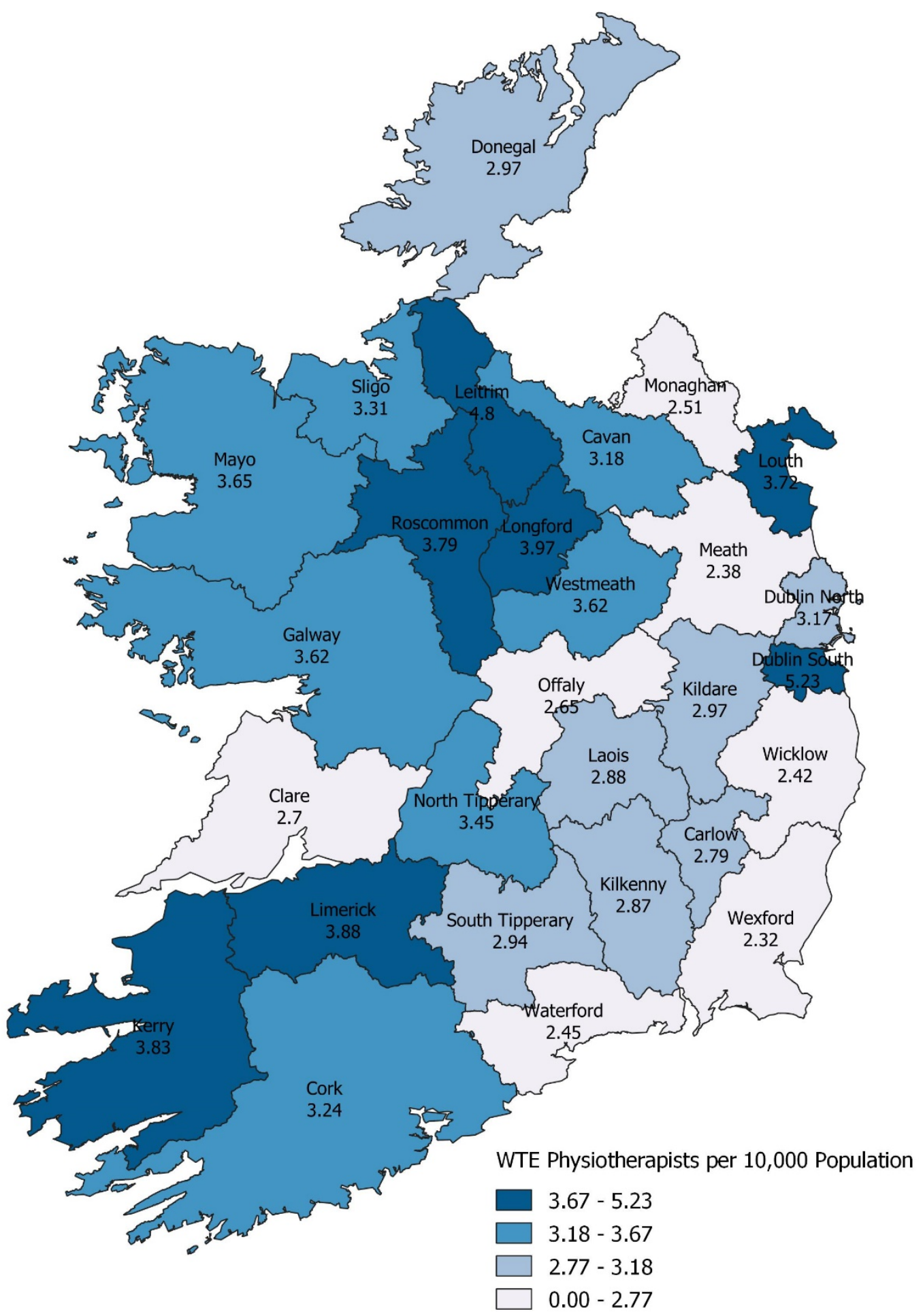


Figure 3: Distribution of WTE non-acute physiotherapists per 10,000 population in Ireland (2014/2015)

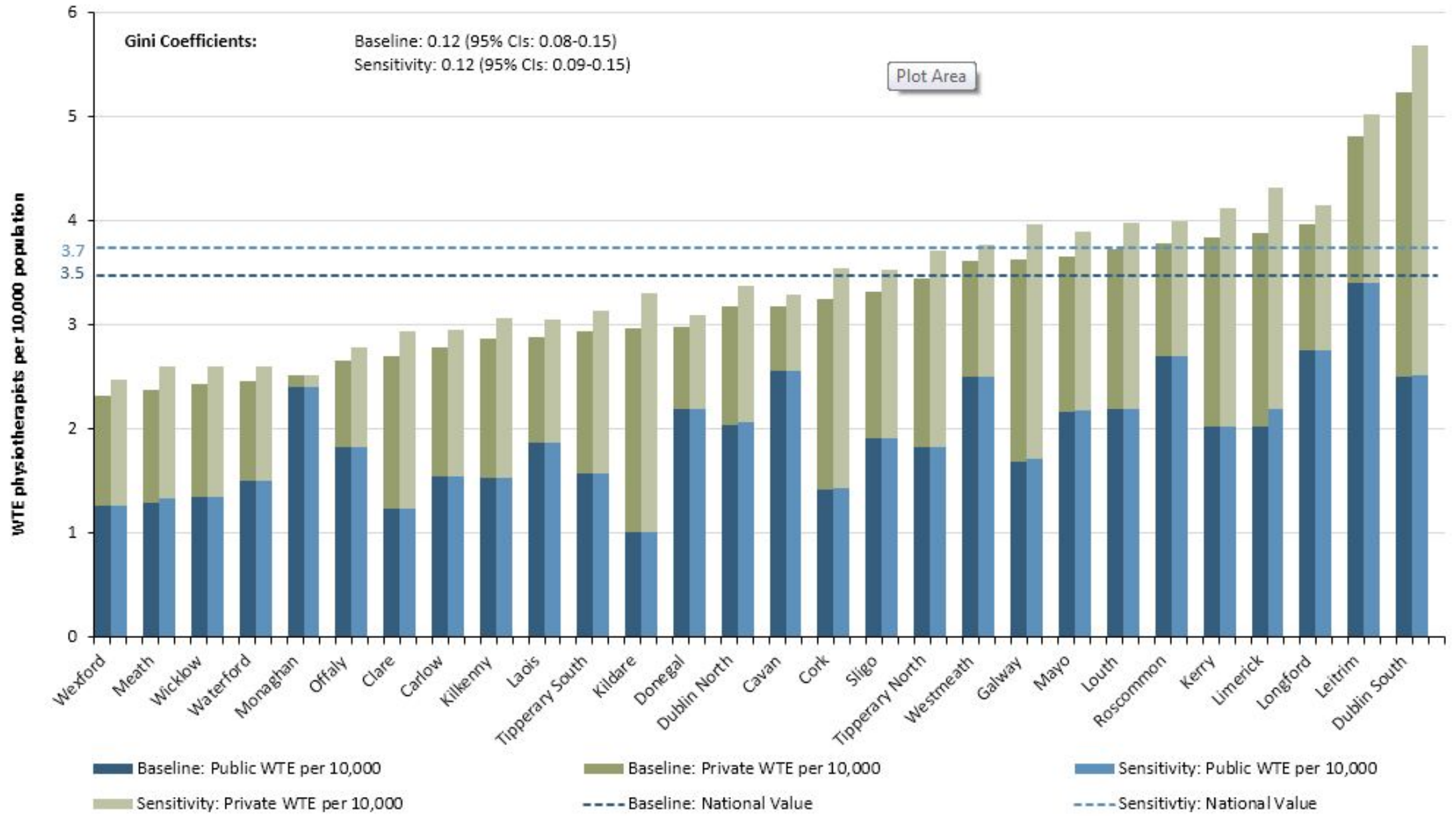

Notes: The number for Dublin South includes 32.5 WTEs employed in a facility which also covers individuals from outside Dublin South. If these are excluded from the geographic analysis Dublin South has a total WTE of 4.77 per 10,000 population (second behind Leitrim) under the baseline scenario and 5.21 per 10,000 people (first in the ranking) in the sensitivity scenario. 
Figure 4: Scatter plot of location quotients of the estimated number of WTE physiotherapists per 10,000 total population and per a mortality, b disability and c medical card (public physiotherapy supply only).

a.) Mortality

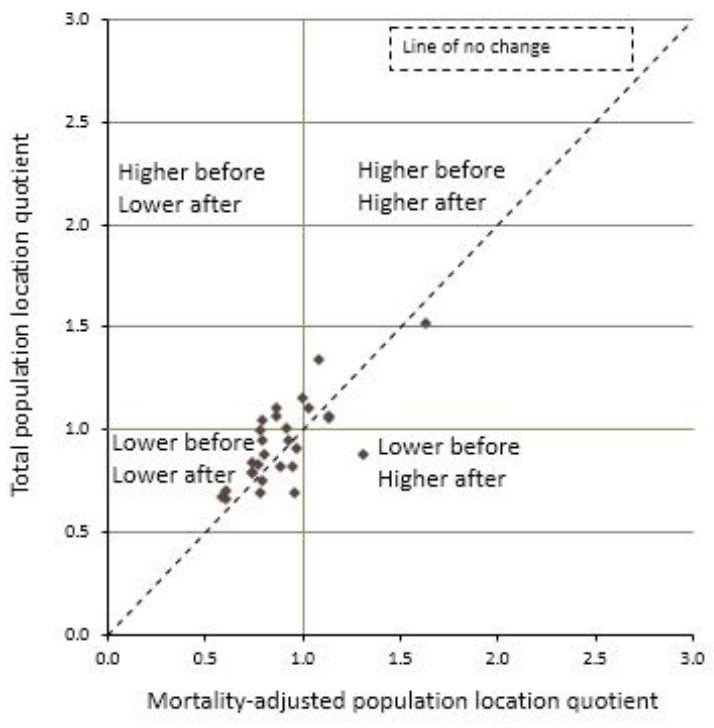

c.) Medical Card (Public Physiotherpy Supply Only)

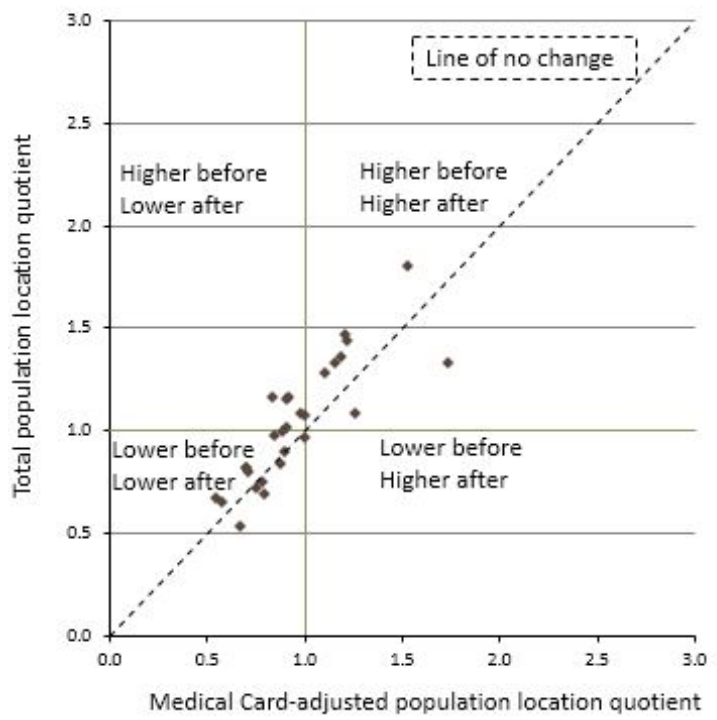

b.) Disability

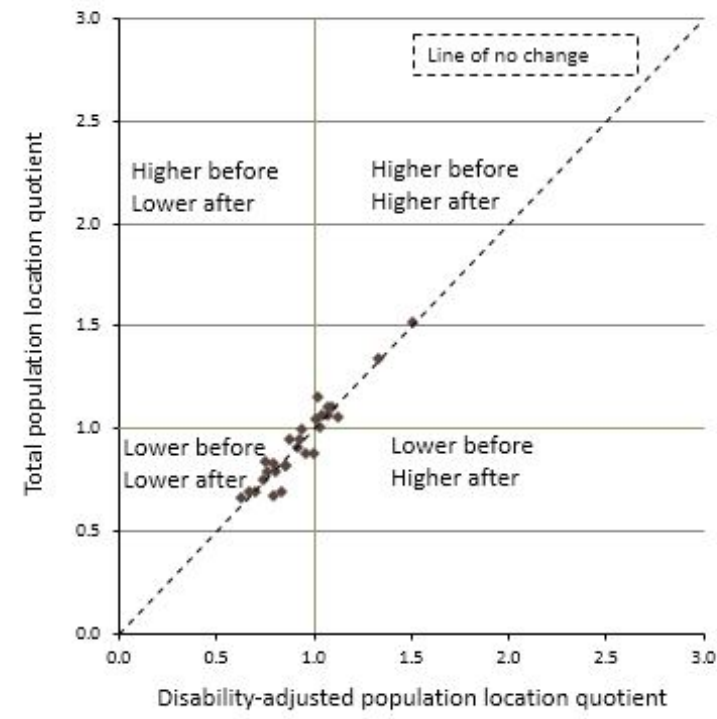

Notes: a)

A county's location quotient is the area value divided by the national value.

b) 'Lower before' means lower than the national value before adjustment. 'Lower after' means lower than the national value after adjustment. 'Higher before' means higher than the national value before adjustment. 'Higher after' means higher than the national value after adjustment 